\title{
Compact Micro Patch antenna with F Shape Extension DGS
}

\author{
G.Vinutna Ujwala, N.Manisha, K.Sridevi
}

\begin{abstract}
This work describes a compact microstrip antenna design for wide bandwidth applications. The proposed work introduces a methodology to improve the bandwidth, as well return loss by the defective ground structure (Extended F-Shape). As communication systems require small size, broadband and multiband frequency antennas, an inset line feed monopoles have to be ensured for fabricating broadband antennas. Intensive investigations are carried out in the proposed work to design a new antenna with broadband and multi-band properties. Simulations are performed by using the Ansoft HFSS Electromagnetic Simulation Software.
\end{abstract}

Keywords : : Defected ground structure (DGS) micro strip antenna, Return Loss.

\section{INTRODUCTION}

The microstrip antennae are broadly used in region of radio frequency as of their ease and compatibility with printed circuit board technology. Light weight, low volume \& Conformability are the attractive features of this antenna. These antennae can be integrated with printed strip line feed networks and their active devices [1-2]. Microstrip patch antenna has dielectric substrate covered with one side radiating element and other side is ground. The dielectric constant has a different value for different substrate material .The dimensions of a patch are very small as compared to substrate material and ground. The microstrip patch antenna dimensions depends on the frequency wavelength of running frequency of resonant frequency. They are different feed techniques are available for different shape of microstrip patch antenna. Feeding techniques are classified in two types there are contacting and non contacting methods. In contacting method are the coaxial probe and microstrip line and non contacting method are proximity coupling and aperture coupling. These are four most popular feed techniques for antenna [2-3]. The advantages of microstrip antenna are Easy to feed (coaxial cable, microstrip line, etc.). The disadvantages of microstrip antenna are low gain and low efficiency.

Revised Manuscript Received on December 13, 2019.

* Correspondence Author

G.Vinutna Ujwala*, working as Assistant Professor in Pragati Engineering College. Surmapalem India,AP. Email:ujwala4591@gmail.com

N.Manisha, Department of ECE, Research scholar, GITAM,Visakhapatnam,AP. Email manisha.gore@gmail.com

Dr. K.Sridevi, department of ECE, GITAM, Visakhapatnam,AP. Email: sridevi.katamaneni@gitam.edu

\section{DEFECTED GROUND STRUCTURE [DGS]}

Defected Ground structure is realized by an impression of a plain shape with a ground plane. It depends upon the shape and dimensions of the DGS [4]. The shielded current distribution on the ground plane is disturbed, and through the form of the substrate layer and the results of a various propagation of electromagnetic waves has been changed from simple to complex for better results. The shape of an antenna is varying for an easy geometry shape. The different shapes of DGS are shown in Fig: 1

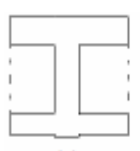

(a)

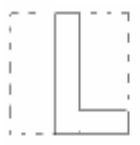

(f)

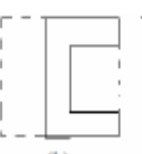

(b)

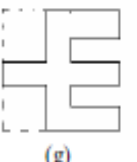

(g)

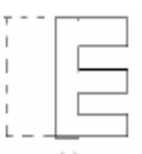

(c)

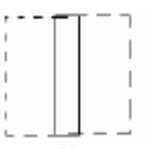

(h)

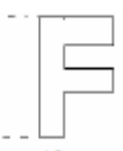

(d)

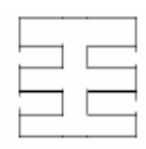

(i)

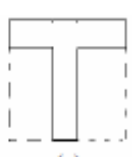

(e)

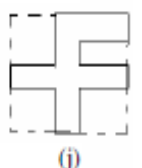

Fig.1: Examples of Defected Ground Structure (DGS)

\section{ANTENNA DESIGN}

Rectangular Micro strip patch antennas have a substrate material with a ground plane. The Antenna parameters are simulated to optimize the performance of the Extended F-Shaped slotted patch antenna for microstrip patch antenna designs. The design method assumes that the specified information includes the dielectric steady of the substrate material and that the height of the substrate is assumed to be:

1. Specify the centre frequency and select a substrate permittivity $\varepsilon_{\gamma}$ and a substrate thickness $h$

$h \geq 0.06 \frac{\lambda}{\sqrt{\varepsilon_{r}}}$

2. $\mathrm{L}_{\mathrm{eff}}=$ Effective length

$$
L_{\text {eff }}=\frac{c}{2 f_{0} \sqrt{\varepsilon_{\text {reff }}}}
$$

$3 . \mathrm{W}=$ Patch width $\mathrm{W}=\frac{c}{2 f_{6} \sqrt{\frac{\varepsilon_{\mathrm{r}}+1}{2}}}$

4. $\varepsilon_{\text {reff }}=$ Permittivity of Effective

$\varepsilon_{\text {reff }}=\frac{\left(\varepsilon_{y}+1\right)}{2}+\frac{\left(\varepsilon_{y}-1\right)}{2}\left(\frac{1}{1+12 \frac{h}{w}}\right)^{1 / 2}$ 


\section{Compact Micro Patch antenna with F Shape Extension DGS}

5. $\Delta \mathrm{L}=$ Change in Length

$$
\Delta \mathrm{L}=0.421 \mathrm{~h} \frac{\left(\varepsilon_{r s f f}+0.9\right)\left(\frac{W}{h}+0.26\right)}{\left(\varepsilon_{r s f f}-0.25\right)\left(\frac{W}{h}+0.8\right)}
$$

6. $\mathrm{L}=$ Length of patch

$$
\mathrm{L}=L_{\text {eff }}-2 \Delta \mathrm{L}
$$

7. $\mathrm{L}_{\mathrm{g}}=$ Length of the Ground

8. $\mathrm{W}_{\mathrm{g}}=$ Width of the Ground

$$
\mathrm{L}_{\mathrm{g}}=\mathrm{L}+6 \mathrm{~h}
$$

$$
\mathrm{W}_{\mathrm{g}}=\mathrm{W}+6 \mathrm{~h}
$$

\section{ANTENNA SIMULATION USING HFSS}

The proposed antenna is designed using HFSS simulation. Track Performance by comparing reflection loss, VSWR antenna gain, and Micro Patch antenna with the advanced DGS system with F-Shape.

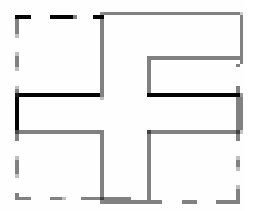

Fig2: The pattern of Extended F shape

The Extended F-shape antenna DGS is simulated by HFSS and resultant designs as shown in Figure. 3 and 4. The parameters of Return loss, Gain \& VSWR are observed at $3.5 \mathrm{GHz}$.

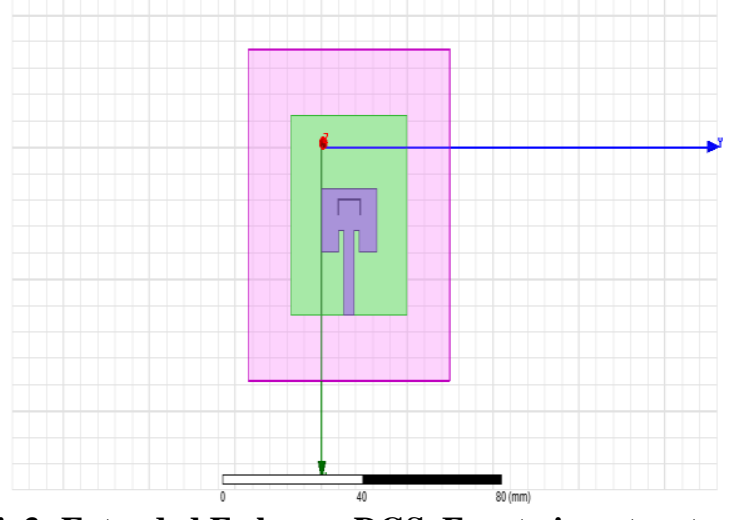

Fig3: Extended F-shape DGS Front view structure

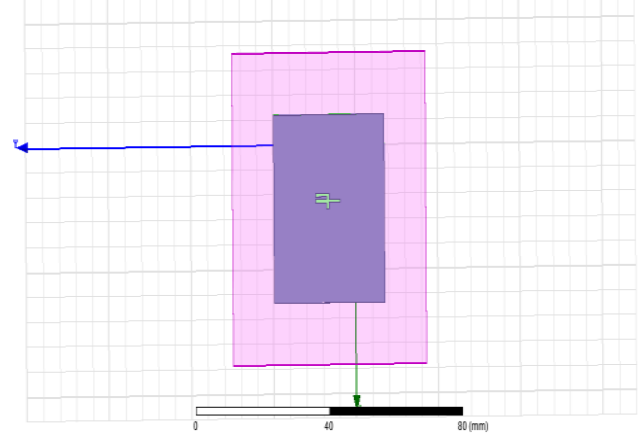

Fig4: Extended F-shape DGS with Back view structure

\section{RESULT AND DISCUSSIONS}

\section{Simulation Results}

\section{Return loss}

Loss of return is another way to express mismatch of an antenna with an extended DGS F-shaped is shown in Fig. 5.

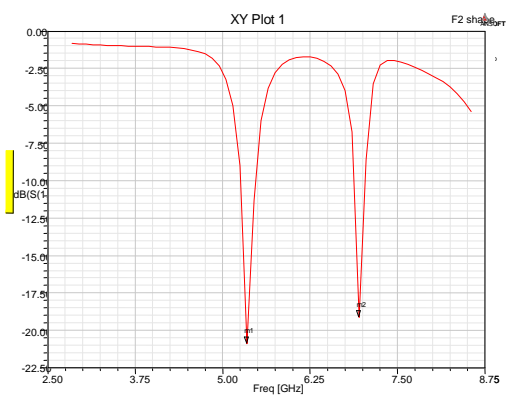

Fig:.5: Extended F-shape DGS Reflection loss of patch antenna

In above figure, the reflection loss was observed to be $-20.88 \mathrm{~dB}$ at $5.35 \mathrm{GHz}$ and $-19.08 \mathrm{~dB}$ at $6.95 \mathrm{GHz}$.

\section{VSWR :}

Basically, VSWR is an impedance variance measurement between the transmitter and the antenna. Simulation results for an antenna with an extended F-shaped DGS are shown in Figure. 6. it should be between 1 and 2 for practical purposes. The VSWR at $5.35 \mathrm{GHz}$ is noted to be 1.19 and $6.95 \mathrm{GHz}$ is 1.24 .

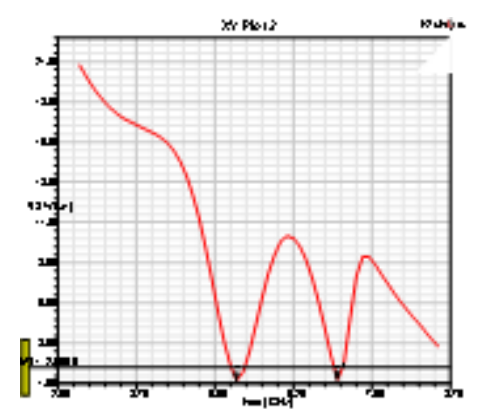

Fig 6: Extended F-shaped DGS VSWR for antenna Gain :

The gain is not more than the power transmits per unit solid angle. The 3D amplification of Extended F-shaped DGS as shown in Fig. 7. The strength of an antenna for any application should be higher than $3 \mathrm{~dB}$. The observed gain for this antenna is $4.24 \mathrm{~dB}$.
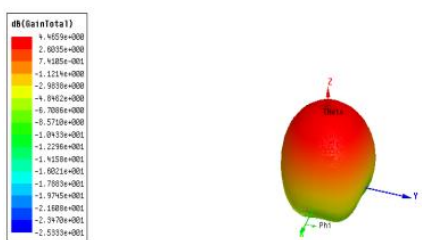

Fig.7: Extended F-shape DGS with 3-D GAIN for antenna Radiation pattern:

Radiation scheme describe the variation in the antenna's radiated power when a function of the antenna's longitudinal direction. This change in power is observed in the far antenna area with respect to the angle of arrival. An extended F-shape DGS Radiated microstrip patch antenna as shown in Fig. 8. 


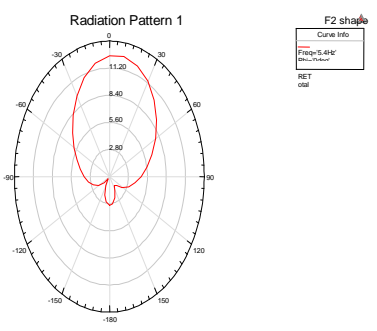

Fig 8: Radiations pattern for Extended F-shape DGS with micro patch antenna

\section{SMITH CHART:}

Smith chart are important graphical tool and the appropriate impedance, the reflection coefficient is equal to 0 and VSWR to 1 . The Smith diagram is essentially a pole diagram of the reflected co-efficient $\mathrm{K}$ can be expressed as normalized impedance. A small antenna chip with an extended F-shaped DGS diagram is shown in Figure 9.

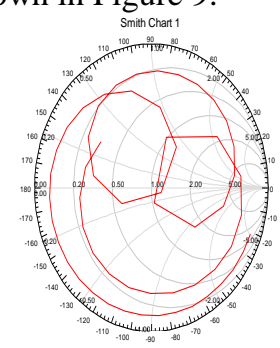

Fig .9: Smith Chart for Extended F-shape DGS

\section{Polarization}

Microstrip antennas with extended F-shaped DGS polarization are shown in Figures 10 and 11

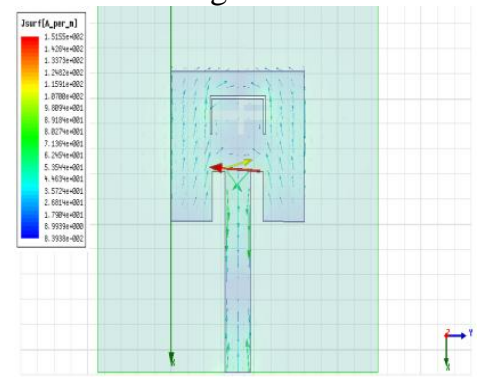

Fig. 10: Extended DGS F-shaped polarization with Front view of microstrip antennas

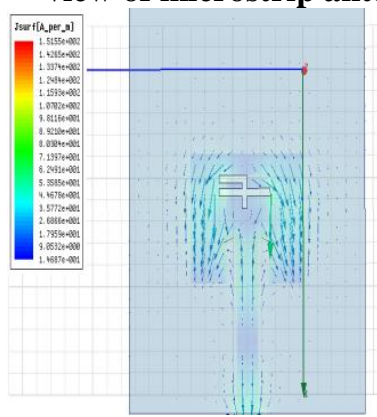

Fig. 11: Extended DGS F-shaped polarization with Back view of micro strip antennas

\section{Current Distribution}

The front and rear distributions of the flow antenna with the DGS F-shaped antenna are shown in the Figures 12 and 13.

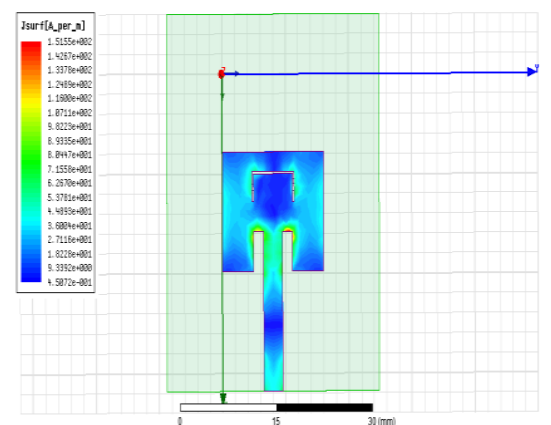

Fig12: Extended F-shaped DGS with front-view current distribution.

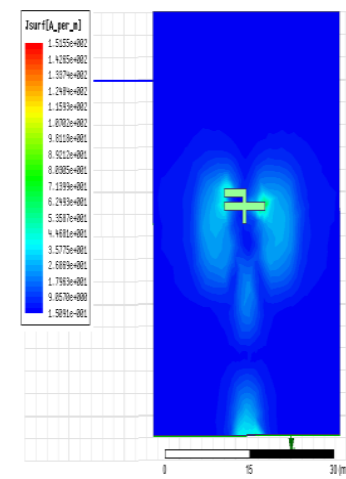

Fig.13: Extended F-shape DGS with Back view Current Distribution

Comparisons of micro strip patch antennas with $\mathbf{F}$ Shape and Extended F - Shape DGS structures:

\begin{tabular}{|l|c|c|c|c|c|}
\hline \multirow{3}{*}{ S.No } & $\begin{array}{c}\text { Micro } \\
\text { Strip } \\
\text { Patch } \\
\text { Antenna }\end{array}$ & $\begin{array}{c}\text { Frequency } \\
\text { Of } \\
\text { Operation } \\
(\mathrm{GHz})\end{array}$ & $\begin{array}{c}\text { Return } \\
\text { Loss } \\
(\mathrm{dB})\end{array}$ & VSWR & $\begin{array}{c}\text { Gain } \\
(\mathrm{dB})\end{array}$ \\
\hline \multirow{3}{*}{1} & & 5.55 & -15.72 & 1.38 & 4.53 \\
& & 7.25 & -13.83 & 1.51 & \\
\hline \multirow{2}{*}{2} & $\square$ & 5.35 & -20.87 & 1.19 & 4.24 \\
& & & & & \\
\hline
\end{tabular}

Table 1: Comparisons of micro strip patch antennas with $\mathrm{F}$ and Extended F DGS structures

\section{CONCLUSION:}

Here, the proposed antenna, based on modelling and optimization, can control the desired resonant frequency of the micro strip antenna using a DGS structure. The comparison results in performance parameters such as back loss from a micro-band-corrected antenna, such as $-20.87 \mathrm{~dB}$ and $-19.09 \mathrm{~dB}$ at $5.35 \mathrm{GHz}$ and $6.95 \mathrm{GHz}$, while the VSWR gave better results due to the extended F-shape.

\section{REFERENCES}

1. International Journals of Emerrging Technology and Advance Engineering (ISSN 22-50-249, ISO 900:2008 Certified Journal, Volume 3, Issue : 7, July -13).' Analysis of Electrical Parameter of Inset Feed Rectangle Micro Patch antennas' (RMPA)' 


\section{Compact Micro Patch antenna with F Shape Extension DGS}

2. Constantie A.Blannis, Antenna Theory - Analysis and Designed, JohnWilley \& Son, INC, third Edition.

3. AJER e-ISSN : 2320-O847 p-ISSN -0936 Volume-O2, Issue09, pp-23-3O., "Enhance the Band -width of a Micro strip Patch Antennas Slots Shape- Patch",

4. IJATCSE, "Designed and Character of E-Shaped Micro strip Patch Antennas for a Wireless: Communications", Vol.2, No.2, Page: 177-180 (2013)

5. International Journal of u- and e- Service, 'Performance Comparison of Microstrip Antenna with Different Shape of the Patch', IJUCST, Vol: 6, No. 3, June, $2 \mathrm{O} 13$.

6. F-G., Zhu, J.-D., Xu, and Xo -u, Q: 'Reductions of mutualed coupling between closeley packed antennas element use of defected ground structures “,Electrons. Let, 2OO9,5, (12), pp. 601-602

7. Kasabe gouda, V. G. and Vino, Progress in Electro magnetics Research, "A broad suspend micro antenna for circular polarized," PIER 9, 3-53-3-68, 2009.

8. Alboyeh, M. N. Kamjai, and M. Shobeyi, Progress in Electro-magnetics Research Letters, "A novel cross-slot geometry to improve impedance band width of micro strip antenna,", Vol. 4, 63-72, 2008.

9. M.G Zhang, S.J Hong and Z. Wang, Progress in Electro-magnetics Research "Two novel bands-notched UWB sloted antenna feed by micro strip line," PIER 78, 209-218, 2008.

10. Bait-Suwaila, Siddiqui M.M., and Ramahi Omari, M.: 'Mutual coupling reductions between microstrip antenna using slotted complementar split-rings resonator', Antennas Wire. Propag. Lettt.,2010, 7, pp. :876-88

11. T. M. Islam, N. Shaki and N. Misran, Progress In Electro magnetic "Broad band E-H shape micro patch antennas for the wireless system," PIER 163-173: 2009.

\section{AUTHORS PROFILE}

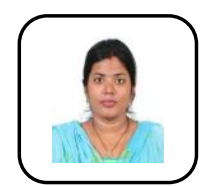

G.Vinutna Ujwala, completed M.Tech. in the stream of Computers \& Communication Engineering from JNTUK Engineering College, Kakinada in the year of 2013 and pursuing Ph.D at GITAM university, Visakhapatnam. Currently working as Assistant Professor in Pragati Engineering College. Surmapalem India. Microwave Patch antennas and VLSI are the interest areas.

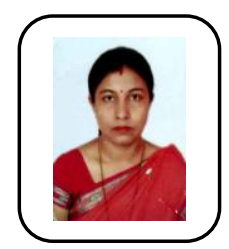

N. Manisha received the B.E. degree in electronics engineering fromShivaji University, Kolhapur, India and M.Tech. degree in Embedded Systems and VLSI from Jawaharlal Nehru Technological University, Hyderabad in 2011. She has 4 years of industrial and more than 5 years of teaching experience. Her research interests are digital signal and image processing and antennas. Manisha is a member of IEEE and ISTE

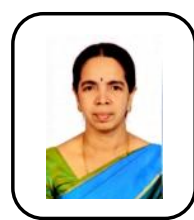

K. Sridevi, received her B.Tech degree in Electronics and Communication Engineering from Nagarjuna University, Andhra Pradesh and M.Tech in Digital Systems and Computer Electronics from JNTU, Hyderabad, India. She received her Ph.D from GITAM University. She is currently working as an Associate Professor in the Department of Electrical, Electronics and Communication Engineering, GITAM University, Visakhapatnam, Andhra Pradesh, India. She published more than 24 Research papers in refereed International journals, International \& National Conferences. Her fields of interest includes signal processing and VLSI. 